\title{
Viabilidad del uso de suero de quesería como base del medio de cultivo de la cepa nativa probiótica Lactobacillus paracasei HA9-2
}

\author{
Vázquez, S. ${ }^{(1)}$, Crosa, M. J. ${ }^{(2)}$, Rey, F. ${ }^{(1)}$, Lopretti, M. ${ }^{(1)}$ \\ Contacto: frey@latu.org.uy \\ (1) Departamento de Biotecnología y Bioprocesos. Gerencia de Proyectos Generales. Laboratorio Tecnológico del Uruguay \\ (LATU) - (2) Gerencia de Proyectos Alimentarios. Laboratorio Tecnológico del Uruguay (LATU). \\ Recibido: 30/6/2009 - Aprobado: 13/11/2009
}

\begin{abstract}
$\underline{\text { Resumen }}$
El suero de quesería constituye un importante residuo de la industria láctea en Uruguay, por lo cual es importante encontrar alternativas viables para su uso. En este trabajo se evaluó el suero de queso como base para el desarrollo de un medio de cultivo de la cepa probiótica nativa Lactobacillus paracasei HA9-2. Se ensayaron diferentes concentraciones de carbohidratos y se evaluaron los efectos del agregado de sales como sulfato de magnesio y manganeso, una fuente de nitrógeno y del prebiótico comercial goma de acacia. A efectos comparativos se realizaron cultivos en MRS, medio específico para bacterias lácticas.

Los resultados obtenidos indican que el suero de queso con una concentración de carbohidratos de $70 \mathrm{~g} / \mathrm{l}$ es un medio óptimo para el desarrollo de esta cepa. Tanto el agregado de sales como de fuente de nitrógeno y prebiótico producen mejoras importantes en la biomasa. Pero en el balance de costos realizado, al comparar la formulación del medio con el incremento de la biomasa producida, se concluye que el suero de queso como único componente es el óptimo para el cultivo de la cepa probiótica HA9-2. Asimismo, se probó el efecto prebiótico de la goma de acacia sobre esta cepa.

Palabras clave: probiótico, prebiótico, suero de queso.
\end{abstract}

\begin{abstract}
The cheese whey is an important residue of the dairy industry in Uruguay, so it is necessary to find new viable alternatives for its use. We evaluated the cheese whey as a base for the development of a probiotic native Lactobacillus paracasei HA9-2 strain culture media. Several carbohydrate concentrations, salt effects as magnesium sulfate and manganese sulfate, a nitrogen source and a commercial prebiotic addition as acacia rubber were assayed. Comparative assays in lactic bacteria commercial media known as MRS were made. The results indicate that the cheese whey with $70 \mathrm{~g} / \mathrm{l}$ of carbohydrates is an ideal media for the strain development. The salt addition as well as the nitrogen source and commercial prebiotic addition improve and increase the biomass. Finally, if we analyze the costs balance, and we compare the costs of the media and the increase of the biomass, we can conclude that the cheese whey is the best for the HA9-2 probiotic strain as the only component of the media. The acacia rubber prebiotic effect on this strain was also tested.

Keywords: probiotic, prebiotic, cheese whey.
\end{abstract}

\section{Introducción}

El suero de queso constituye un importante desecho de la industria láctea. Si bien su composición es variada y depende del tipo de queso del que proviene, retiene hasta el $55 \%$ de los nutrientes de la leche, como la lactosa, proteínas solubles, lípidos y sales minerales (Panesar et al., 2007). Por este motivo y por los importantes problemas de contaminación que genera su descarte como efluente -presenta un índice de DBO (demanda biológica de oxígeno) de 5,20-, sus usos alternativos constituyen un tema de investigación activa (Zumbado, Esquivel y Worng, 2006).

La utilización del suero como tal es un gran problema, por la dificultad de su transporte y del mantenimiento de condiciones microbiológicamente aceptables, ya que es susceptible a la contaminación por bacterias, hongos y fagos (Zumbado, Esquivel y Worng, 2006). Para solucionar esta dificultad, existen varias empresas en nuestro país que transforman el suero de queso en polvo. Recientemente comenzaron obras en la empresa PILI para construir una planta dedicada a procesar el suero de queso. Se espera que procese 220.000 litros de suero por día.

Uno de los aprovechamientos estudiados para el suero de queso es su bioutilización para producir ácido láctico por Lactobacillus casei en un sistema de células inmovilizadas (Panesar et al., 2007).

Es sabido que los Lactobacillus son bacterias muy exigentes en factores de crecimiento; son varios los trabajos que reportan la inclusión en el medio de extracto de levaduras o lisado de proteínas, sulfato de magnesio, sulfato de manganeso y vitaminas para mejorar la producción de ácido láctico en suero (Panesar et al., 2007; Aeshlimann y Von Stockar, 1990; Arasaratnam, Senthuran y Balasubramaniam, 1996).

También se ha reportado la producción de ácido láctico a partir de lactosuero por varias especies de Lactobacillus, ensayando diferentes concentraciones de suero entre 20 y 100 g/l en reactores operando en modo batch y continuo, con diferentes aditivos, como extracto y sales, y diferentes condiciones de agitación (Serna y Rodríguez, 2005; Tango y Ghaley, 1999a). Tango (1999b) ha descrito la utilización de suero de queso para producción de ácido láctico por Lactobacillus helveticus en condiciones batch con un control continuo de temperatura y $\mathrm{pH}$ para lograr mejores rendimientos de biomasa y de ácido láctico. El foco de los estudios anteriores en el ácido láctico radica en sus variadas aplicaciones en la industria alimentaria, química y farmacéutica.

Macedo et al. (2002) han estudiado el efecto de suplementar el medio en base a suero con sales y vitaminas para la producción de 
exopolisacáridos (EPS) por parte de Lactobacillus rhamnosus RW9595M, llegando a la conclusión que en el suero con sales y vitaminas se lograban las producciones de EPS más altas reportadas hasta la fecha.

Se ha planteado la aptitud del suero de leche de cabra como sustrato para el desarrollo de un producto fermentado probiótico con Bifidobacterium bifidum y Lactobacillus acidophilus (Lomas de León y Rojas, 2005).

Más recientemente, Zumbado et al. (2006) desarrollaron un medio en base a suero de quesería para la producción de biomasa por tres levaduras (Klyveromices marxianus, Candide kefyr y Saccharomyces cerevisiae), con el objetivo de producción de proteínas para alimentación animal.

El objetivo de este trabajo es el desarrollo de un medio en base a suero de quesería para el cultivo de la cepa Lactobacillus paracasei HA9-2. Es una cepa nativa, de origen humano, identificada como Lactobacillus paracasei por ensayos moleculares y denominada HA92 (Vázquez et al., 2007). Su cultivo en suero presenta la ventaja de su adaptación a un medio similar al de los productos en los cuales es factible su incorporación, entre ellos yogur y queso probiótico.

Debido a la importancia reportada por numerosos autores de la presencia de sales en la conversión de glucosa a ácido láctico por las bacterias lácticas, se estudiaron distintas formulaciones de medios de cultivo en base a suero de queso suplementado con sales (Panesar et al., 2007; Waldir et al., 2007; Xu et al., 2006).

\section{Materiales y Métodos}

\section{Cepa bacteriana}

La cepa denominada HA-9, nativa, de origen humano, fue identificada como Lactobacillus paracasei por ensayos moleculares. La misma se encuentra en el Banco de Cepas del Laboratorio Tecnológico del Uruguay, conservada a $-20^{\circ} \mathrm{C}$ en leche y glicerol.

\section{Evaluación de diferentes concentraciones de suero}

Se realizaron dos pasajes en MRS de la cepa realizando cultivos overnight en condiciones de microaerobiosis a $37{ }^{\circ} \mathrm{C}$ sin agitación para el desarrollo del inóculo de las fermentaciones. Se ajustó la concentración del inóculo en 1,0x108 ufc/ml por espectrofotometría. Se inocularon diferentes matraces de $500 \mathrm{ml}$ al 1,0\% conteniendo 400 $\mathrm{ml}$ de suero de queso en concentraciones de carbohidratos de $20 \mathrm{~g} / \mathrm{L}, 50$ g/L y 70 g/L y MRS estéril. El suero de queso fue previamente tratado térmicamente a $100{ }^{\circ} \mathrm{C}$ durante 30 minutos. Por tratarse de un medio no translúcido, su esterilidad se verificó por recuentos posteriores a su incubación a $37{ }^{\circ} \mathrm{C}$ durante 24 horas. Se condujeron ensayos por duplicado. Se utilizaron como control matraces sin inocular. En los cultivos se evaluaron las unidades formadoras de colonias a diferentes tiempos por recuento en placa de MRS y en los medios en base a suero la producción de ácidos orgánicos por titulación con $\mathrm{NaOH} 0,1 \mathrm{~N}$.

\section{Agregado de magnesio, manganeso, extracto de levadura y prebiótico}

Se realizaron fermentaciones en batch en diferentes medios:

i) suero de queso $70 \mathrm{~g} / \mathrm{l}$ de carbohidratos;

ii) suero de queso suplementado con sulfato de magnesio hepta hidratado $0.3 \mathrm{~g} / 1$ y sulfato de manganeso tetra hidratado $0.03 \mathrm{~g} / 1$;

iii) suero de queso suplementado con sulfato de magnesio hepta hidratado $0.3 \mathrm{~g} / 1$, sulfato de manganeso tetra hidratado $0.03 \mathrm{~g} / 1 \mathrm{y}$ extracto de levadura al $0.5 \% \mathrm{p} / \mathrm{v}$;

iv) suero de queso $70 \mathrm{~g} / 1 \mathrm{de}$ carbohidratos suplementado con prebiótico (Fibergum) al $0,5 \%$ y al $1 \% \mathrm{p} / \mathrm{v}$. Se condujo un ensayo por duplicado utilizando como blanco un matraz de cada uno de los medios sin inocular.
El desarrollo del inóculo y las fermentaciones se efectuaron de la misma forma que en los ensayos anteriores. En los cultivos se evaluaron las unidades formadoras de colonias a diferentes tiempos por recuento en placa de MRS y el cambio de $\mathrm{pH}$ en el medio de cultivo a lo largo de la fermentación. El agregado de extracto de levadura modifica el color del medio dificultando la determinación del punto final de la titulación con $\mathrm{NaOH}$, por lo que se realizaron medidas directas de $\mathrm{pH}$.

\section{Evaluación de diferentes valores de pH en el desarrollo de los cultivos}

Se realizaron fermentaciones en batch en suero de queso $(70 \mathrm{~g} / \mathrm{L}$ de carbohidratos) a pH 5,0, 5,5 y 6,0. El pH, tanto en el control como en los ensayos, fue mantenido utilizando $\mathrm{HCl} 10 \mathrm{~N}$ y $\mathrm{NaOH} 10 \mathrm{~N}$ esterilizados por filtración. Los ensayos fueron seguidos por recuento a diferentes tiempos y el pH se controló cada una hora.

\section{Viabilidad económica de los medios evaluados}

En primer lugar, se evaluó la factibilidad económica de la utilización del suero de queso como medio para la fermentación utilizando como referencia el MRS, un medio sintético óptimo para el desarrollo de Lactobacillus. Para ello se realizó una comparación de los costos para un reactor de 1000 litros.

En segundo lugar, se evaluó la factibilidad económica de la utilización de suero de queso, suero con agregado de extracto de levadura y suero con agregado de prebiótico. Se determinaron los costos de las distintas formulaciones para un reactor de 1000 litros y se hizo un balance entre los costos y la producción de biomasa.

\section{Resultados y Discusión}

\section{Evaluación de diferentes concentraciones de suero}

La mayor producción de ácido y de biomasa se dio en el suero de 70 g/l de carbohidratos, como se observa en el Gráfico 1 y la Tabla 1. En las curvas de crecimiento (Gráfico 2) se observa que la cepa presenta una fase lag de aproximadamente dos horas, lo que permite concluir que es una cepa adaptada a este tipo de medio.

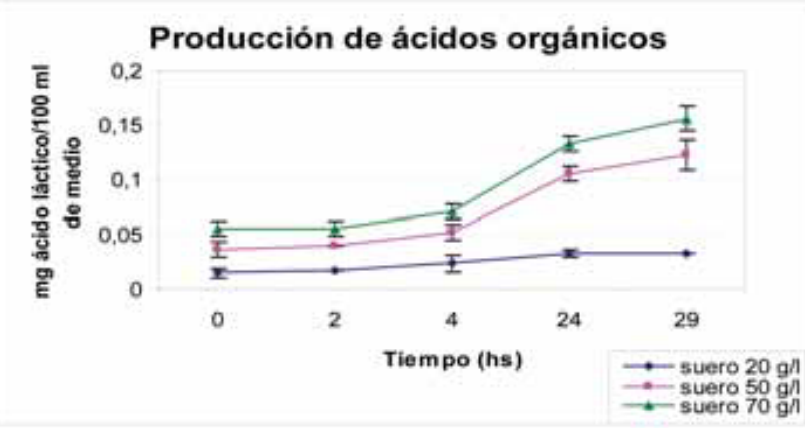

Gráfico 1. Producción de ácidos orgánicos determinada por valoración con $\mathrm{NaOH}$ a diferentes tiempos de fermentación. 


\section{Ln de la Biomasa producida a diferentes} concentraciones de suero

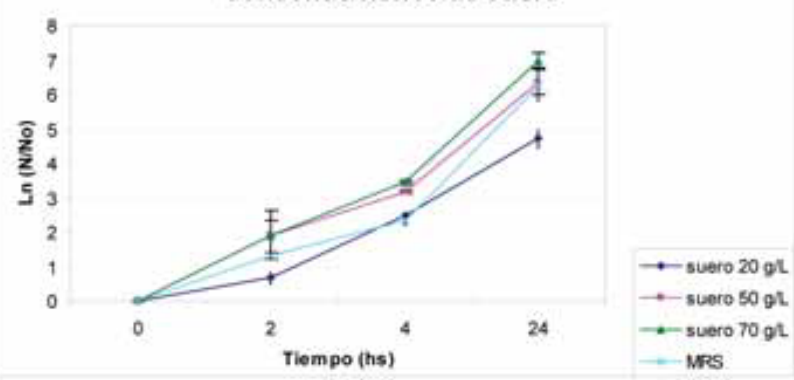

Gráfico 2. Logaritmo Neperiano de unidades formadores de colonia por mililitro en función del tiempo de fermentación.

En la Tabla 1 se presentan algunos parámetros de las fermentaciones realizadas en batch en el suero con distintas concentraciones de carbohidratos, a modo de presentar el número de células iniciales, finales, fase lag, N/No. La fase exponencial no se pudo determinar con exactitud en esta experiencia y por este motivo no pudo calcularse la velocidad específica de crecimiento $(\mu)$.

\begin{tabular}{|l|c|c|c|c|}
\hline Parámetros & Suero $20 \mathrm{~g} / 1$ & Suero $50 \mathrm{~g} / 1$ & Suero $70 \mathrm{~g} / \mathrm{l}$ & MRS control \\
\hline Fase lag (hs) & 2 & 2 & 2 & 2 \\
\hline $\begin{array}{l}\text { Nümero } \\
\text { de células inicial }\end{array}$ & $\mathbf{5 , 2 0 \mathrm { E } + 0 6}$ & $\mathbf{3 , 5 0 \mathrm { E } + 0 6}$ & $\mathbf{2 , 8 0 \mathrm { E } + 0 6}$ & $\mathbf{4 , 9 0 \mathrm { E } + 0 6}$ \\
$\begin{array}{l}\text { Número final } \\
\text { de células }\end{array}$ & $5,80 \mathrm{E}+08$ & $2,04 \mathrm{E}+09$ & $3,04 \mathrm{E}+09$ & $2,58 \mathrm{E}+09$ \\
\hline N/No & $\mathbf{1 1 1}$ & $\mathbf{5 8 3}$ & $\mathbf{1 2 1 4}$ & $\mathbf{5 2 6}$ \\
\hline
\end{tabular}

Tabla 1. Algunos parámetros de las fermentaciones en las diferentes concentraciones de suero de queso realizadas en batch y en MRS como control.

No se pudo obtener la concentración de ácido láctico en MRS por titulación con $\mathrm{NaOH}$ debido a que el color del medio impidió determinar el punto final.

\section{Agregado de magnesio, manganeso, extracto de levadura y prebiótico}

Las variaciones del $\mathrm{pH}$ a lo largo de las fermentaciones se expresan en el Gráfico 3. Se observa que en el suero suplementado con sales y extracto de levadura se produce una acidificación mayor del medio en comparación con el suero sin suplementar. Las diferencias de acidificación entre el suero sin suplementar y el suplementado sólo con sales no son significativas. No se presentan variaciones en la duración de la fase lag (aproximadamente dos horas) entre los diferentes medios, por lo que las variaciones observadas en el $\mathrm{pH}$ no se deben a diferencias en las adaptaciones a los medios.

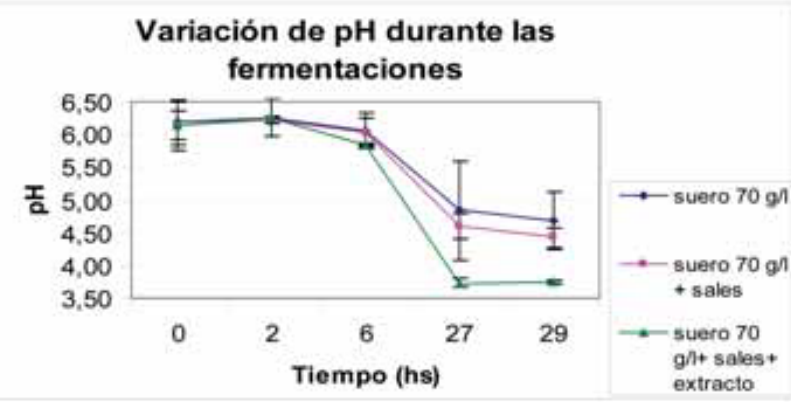

Gráfico 3. Variación del pH debida a la suplementación del medio con sales y extracto de levadura.
Los resultados de producción de biomasa (Tabla 2) indican un mayor crecimiento en el suero con extracto de levadura y sales, triplicándose al cabo de 24 hs de fermentación.

\begin{tabular}{|c|c|c|c|}
\hline Parámetros & Suero $70 \mathrm{~g} / 1$ & $\begin{array}{c}\text { Suero } 70 \mathrm{~g} / \mathrm{l} \\
+ \text { sales }\end{array}$ & $\begin{array}{c}\text { Suero } 70 \mathrm{~g} / 1 \\
+ \text { sales } \\
+ \text { extracto de } \\
\text { levadura }\end{array}$ \\
\hline Fase lag (hs) & 2 & 2 & 2 \\
\hline $\begin{array}{l}\text { Nùmero } \\
\text { de celulas inicial }\end{array}$ & $4,37 \mathrm{E}+06$ & $5,73 E+06$ & $3,77 \mathrm{E}+06$ \\
\hline $\begin{array}{l}\text { Número final } \\
\text { de células }\end{array}$ & $1,50 E+09$ & $1,78 E+09$ & $3,53 E+09$ \\
\hline $\mathrm{N} / \mathrm{No}$ & 345 & 313 & 961 \\
\hline
\end{tabular}

Tabla 2. Parámetros de las fermentaciones en batch en suero $70 \mathrm{~g} / \mathrm{l}$ suplementado.

En el Gráfico 4 se presentan las curvas de crecimiento de la cepa en distintas formulaciones de medio. No se observan diferencias de comportamiento entre el suero y el suero suplementado con sales. Se observa un cambio en la cinética de crecimiento de la bacteria en el suero suplementado con sales y extracto de levadura.

\section{Ln Biomasa producida en diferentes formulaciones de medio}

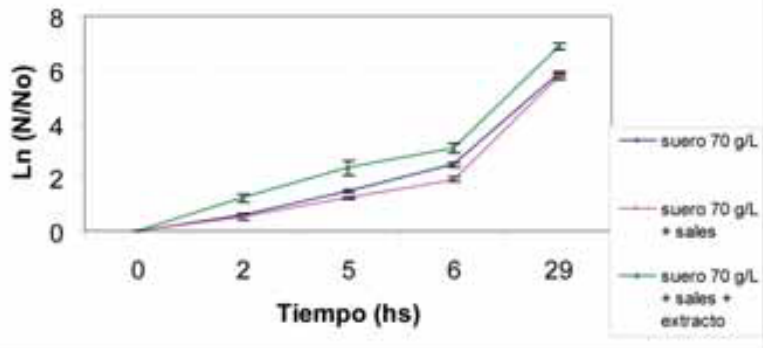

Gráfico 4. Logaritmo neperiano de la variación de la biomasa generada debida a la suplementación del medio con sales y extracto de levadura.

En relación al efecto del prebiótico, no se producen diferencias significativas de la cinética de crecimiento entre los cultivos en suero, en suero con prebiótico al 0,5\% y suero con prebiótico al $1 \%$ (Gráfico 5). Se observa un aumento del $32 \%$ de biomasa al suplementar el medio con el prebiótico al 0,5\% (Tabla 3 ).

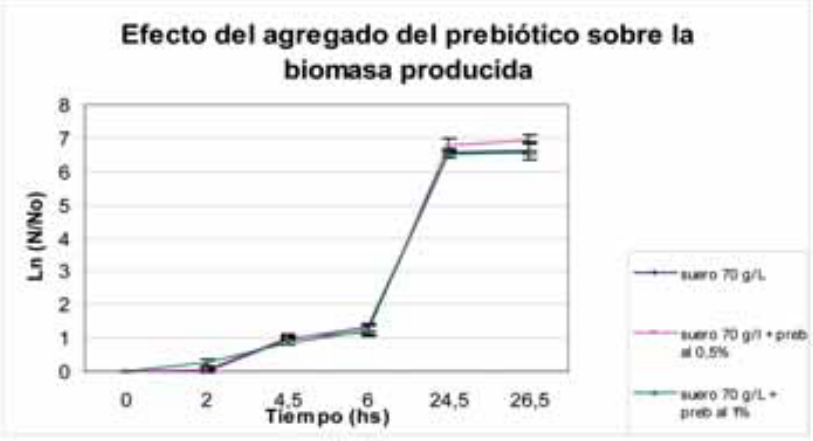

Gráfico 5. Logaritmo neperiano de la relación de biomasa (N) vs. biomasa al inicio de la fermentación (No) en función del tiempo. 


\begin{tabular}{|c|c|c|c|}
\hline Parámetros & Suero $70 \mathrm{~g} / 1$ & $\begin{array}{c}\text { Suero } 70 \mathrm{~g} / 1 \\
\text { + prwhiótice al } 6.5 \%\end{array}$ & $\begin{array}{r}\text { Suero } 70 \mathrm{~g} / 1 \\
+ \text { prebiatice al } 1 \%\end{array}$ \\
\hline Fase lag (hs) & 2 & 2 & 2 \\
\hline $\begin{array}{l}\text { Número } \\
\text { de células inicial }\end{array}$ & $5,85 \mathrm{E}+06$ & $6,50 \mathrm{E}+06$ & $6,15 E+06$ \\
\hline $\begin{array}{l}\text { Nủmero final } \\
\text { de células }\end{array}$ & $4,60 \mathrm{E}+09$ & $6.75 \mathrm{E}+09$ & $4,33 E+09$ \\
\hline N/No & 766 & 1044 & 706 \\
\hline
\end{tabular}

Tabla 3. Parámetros de las fermentaciones batch en suero $70 \mathrm{~g} / \mathrm{l}$ suplementado con diferentes concentraciones de prebiótico.

\section{Evaluación de diferentes valores de pH en el desarrollo de los cultivos}

En el Gráfico 6 se observa el efecto del $\mathrm{pH}$ en la cinética de crecimiento de los cultivos en suero con $70 \mathrm{~g} / \mathrm{l}$ de carbohidratos. Se produce un mayor desarrollo de esta cepa de $L$. paracase $i$ a pH 6,0; se determinó una relación de N/No final de 6,1, mientras que para pH 5,0 la misma es de 2,94 y a pH 5,5 es 4,76 .

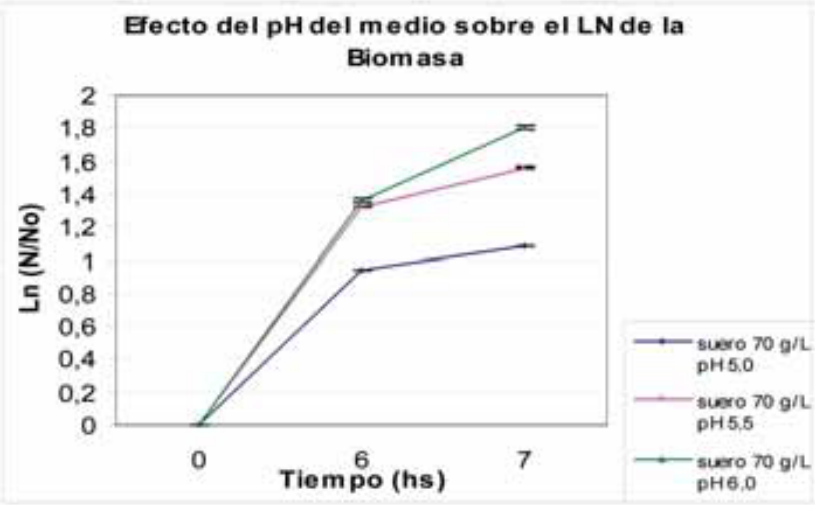

Gráfico 6. Curva de crecimiento a diferentes valores de $\mathrm{pH}$ utilizando el suero de queso como medio para la fermentación, expresada como N/No en función del tiempo.

\section{Viabilidad económica de los medios evaluados}

En la Tabla 4 se presentan los costos de formulación de los diferentes medios de cultivo.

\begin{tabular}{|l|c|c|c|c|}
\cline { 3 - 5 } \multicolumn{2}{c}{} & \multicolumn{2}{c|}{$\begin{array}{c}\text { Suero de } 70 \mathrm{~g} / \text { litro } \\
\text { con los suplementos }\end{array}$} \\
\cline { 2 - 5 } \multicolumn{1}{c|}{} & \multicolumn{1}{c|}{$\begin{array}{c}\text { MRS } \\
\text { reconstituido }\end{array}$} & $\begin{array}{c}\text { Suero } \\
\mathbf{7 0} \mathrm{g} / 1\end{array}$ & $\begin{array}{c}\text { con extracto } \\
\text { de levadura }\end{array}$ & $\begin{array}{c}\text { con } \\
\text { prebiótico }\end{array}$ \\
\hline $\begin{array}{l}\text { Costo } \\
\text { (US } 5 / 1000 \text { litros) }\end{array}$ & 11550 & 210 & 1088 & 276 \\
\hline
\end{tabular}

Tabla 4. Costo de formulación de los medios de cultivo.

El agregado de extracto de levadura al suero de queso aporta nutrientes importantes para el desarrollo de la cepa HA9-2, provocando un aumento de casi el triple de producción de biomasa (Tabla 2). Sin embargo, el costo de formulación del suero con extracto de levadura es cinco veces mayor al costo del suero de $70 \mathrm{~g} / 1$, no resultando económicamente viable.

La inclusión del prebiótico en el medio de cultivo provoca un incremento de la biomasa producida del $36 \%$ (Tabla 3). Si bien el incremento en el costo de formulación es del $31,3 \%$, es necesario tener en cuenta en el balance económico el aumento de las actividades necesarias para la producción del medio. El prebiótico debe ser esterilizado por separado antes de incluirlo en el medio, aumentando el consumo de energía y, por consiguiente, el costo del proceso.

\section{Conclusiones}

El desarrollo de la cepa probiótica nativa Lactobacillus paracasei HA9-2 en suero de queso a diferentes concentraciones de carbohidrato fue muy bueno, ya que se obtuvieron concentraciones superiores a las obtenidas en MRS, que es un medio específico para Lactobacillus spp. En el suero de queso con $70 \mathrm{~g} / 1$ de carbohidratos se obtuvieron los mejores resultados de producción de biomasa.

El agregado de las sales sulfato de magnesio y de manganeso no produjo diferencias importantes que justifiquen su inclusión en el medio de fermentación. Sin embargo, la inclusión del extracto de levadura conjuntamente con las sales, duplicó la producción de biomasa. Es sabido que los Lactobacillus son bacterias exigentes en metabolitos como vitaminas, aminoácidos y minerales, y que el extracto de levadura aporta principalmente nitrógeno y vitaminas del complejo B. Pero el agregado de extracto presenta la desventaja de aumentar sustancialmente el costo del medio.

Dentro de los valores de $\mathrm{pH}$ ensayados para el suero de queso con $70 \mathrm{~g} / 1$ de carbohidratos como medio de fermentación se producen desarrollos mejores a $\mathrm{pH} \quad 6,0$.

Los resultados obtenidos demostraron el efecto prebiótico de la goma de acacia sobre la cepa HA9-2 de L. paracasei. Asimismo, el poder estabilizante de la fibra sobre las emulsiones en conjunción con el efecto constatado sobre la cepa HA9-2 es un punto de partida para la investigación y diseño de alimentos probióticos. No obstante, en este caso particular no se aconseja su inclusión en el medio de fermentación debido al balance de costos desfavorable.

\section{Reconocimientos}

Agradecemos a Carolina Ottati por su invalorable colaboración.

\section{Referencias}

- AESHLIMANN, A.; VON STOCKAR, U. The effect of yeast extract supplementation on the production of lactic acid from whey permeates by Lactobacillus helveticus. En: Applied Microbiology and Biotechnology. 1990, 32(4):398-402.

- ARASARATNAM, V.; SENTHURAN, A.;

BALASUBRAMANIAM, K. Supplementation of whey with glucose and different nitrogen sources for lactic acid production by Lactobacillus delbrueckii. En: Enzyme and Microbial Technology. 1996, (19):482-486.

- LOMAS DE LEON, Y.; ROJAS, C. Aprovechamiento de suero de leche de cabra como sustrato para el desarrollo de un producto fermentado probiótico con Bifidobacterium bifidum y Lactobacillus acidophilus. En: Universidad de Guanajuato; Universidad de Nuevo León. VII Congreso Nacional de Ciencia de los Alimentos y III Foro de Ciencia y Tecnología de los Alimentos, (Guanajuato 1-3 de octubre 2005). Guanajuato: Universidad de Guanajuato, 2005. pp.475-484.

- MACEDO, M.; LACROIX, C.; GARDNER, J.; CHAMPAGNE, C. Effect of medium supplementation on exopolysaccharide production by Lactobacillus rhamnosus RW-9595M in whey permeate. En: International Dairy Journal. 2002, (12):419-426. PANESAR, P.; KENNEDY, J.M.; GANDHI, D.; BUNKO, K. Bioutilisation of whey for lactic production. En: Food Chemistry. 2007, (105):1-14

- SERNA, L.; RODRIGUEZ, A. Producción biotecnológica de ácido láctico: estado del arte. En: Cienc. Tecnol. Aliment. 2005, $5(1): 54-65$

- TANGO, M.; GHALEY, A. Amelioration of lactic acid production from cheese whey using micro-aeration. En: Biomass and Bioenergy. 1999a, (17):221-238.

- TANGO, M.; GHALEY A. Effect of temperature on lactic acid production from cheese whey using Lactobacillus helveticus under 
batch conditions. En: Biomass and Bioenergy. 1999b, (16):61-78.

- VÁZQUEZ, S.; LOPRETTI, M.; REY, F.; ZUNINO, P.

Aislamiento y caracterización de cepas nativas de Lactobacillus spp. para su uso como probióticos en la industria láctea.

En: INNOTEC. 2007, (2):12-14.

- WALDIR, E.; RYCHTERA, M.; MELZOCH, K.; QUILLAMA, E.; EGOAVIL, E. Producción de ácido láctico por Lactobacillus plantarum L10 en cultivos batch y continuo. En: Revista Peruana de Biología. 2007, 14 (2):271-275.

- XU, G.; CHU, J.; WANG, Y.; ZHUANG, Y.; ZHANG, S.; PENG, H. Development of a continuous cell-recycle fermentation system for production of lactic acid by Lactobacillus paracasei.

En: Process Biochemistry. 2006, (41):2458-2463.

- ZUMBADO, W.; ESQUIVEL, P.; WORNG, E. Selección de una levadura para producción de biomasa, crecimiento en suero de queso. En: Agronomía Mesoamericano. 2006, 17(2):151-160. 